\title{
The Brattleboro Rat Displays a Natural Deficit in Social Discrimination That Is Restored by Clozapine and $A$ Neurotensin Analog
}

\author{
David Feifel*,', Sharon Mexal', Gilia Melendez', Philip YT Liu', Joseph R Goldenberg' and Paul D Shilling' \\ 'Department of Psychiatry, University of California, San Diego Medical Center, San Diego, CA, USA; ${ }^{2}$ Cenomed BioSciences, LLC, Irvine, CA, USA
}

\begin{abstract}
Cognitive deficits in schizophrenia are a major source of dysfunction for which more effective treatments are needed. The vasopressindeficient Brattleboro (BRAT) rat has been shown to have several natural schizophrenia-like deficits, including impairments in prepulse inhibition and memory. We investigated BRAT rats and their parental strain, Long-Evans (LE) rats, in a social discrimination paradigm, which is an ethologically relevant animal test of cognitive deficits of schizophrenia based upon the natural preference of animals to investigate conspecifics. We also investigated the effects of the atypical antipsychotic, clozapine, and the putative antipsychotic, PDI49I63, a brain-penetrating neurotensin-I agonist, on social discrimination in these rats. Adult rats were administered saline or one of the three doses of clozapine $(0.1,1.0$, or $10 \mathrm{mg} / \mathrm{kg}$ ) or PDI $49163(0.1,0.3$, or $1.0 \mathrm{mg} / \mathrm{kg})$, subcutaneously. Following drug administration, adult rats were exposed to a juvenile rat for a 4-min learning period. Animals were then housed individually for 30 min and then simultaneously exposed to the juvenile presented previously and a new juvenile for 4 min. Saline-treated LE rats, but not BRAT rats, exhibited intact social discrimination as evidenced by greater time spent exploring the new juvenile. The highest dose of clozapine and the two highest doses of PDI49/63 restored social discrimination in BRAT rats. These results provide further support for the utility of the BRAT rat as a genetic animal model relevant to schizophrenia and drug discovery. The potential of neurotensin agonists as putative treatments for cognitive deficits of schizophrenia was also supported.

Neuropsychopharmacology (2009) 34, 201 I-20I8; doi:I0. I038/npp.2009. I5; published online 25 March 2009
\end{abstract}

Keywords: animal model; Brattleboro rat; cognitive deficit; social discrimination; schizophrenia; neurotensin

\section{INTRODUCTION}

Cognitive deficits of schizophrenia are a core feature of schizophrenia and several other neuropsychiatric disorders. They are among the first detectable symptoms and are consistent from the first episode throughout middle age (Hagan and Jones, 2005). Evidence suggests that cognitive deficits have strong adverse effects on the functional status of schizophrenia patients (Green et al, 2000, 2004). The Measurement and Treatment Research to Improve Cognition in Schizophrenia (MATRICS) committee identified seven distinct and replicable domains of cognitive deficits of schizophrenia: verbal memory, recognition memory, attention, executive function, social cognition, reasoning, and problem solving (Buchanan et al, 2005 and Green, 2006).

\footnotetext{
* Correspondence: Dr D Feifel, Department of Psychiatry, University of California, San Diego Medical Center, 200 West Arbor Drive, San Diego, CA 92103-8218, USA, Tel: + 6195432485 ,

Fax: +619543 3738, E-mail: dfeifel@ucsd.edu

Received 25 August 2008; revised 5 January 2009; accepted 6 January 2009
}

Antipsychotic drugs in use at present have, at best, modest effects on cognitive deficits of schizophrenia in the vast majority of schizophrenia patients (Gold, 2004; Hagan and Jones, 2005). There is strong evidence that atypical antipsychotics generally produce an incomplete amelioration of cognitive deficits of schizophrenia, whereas there is controversy regarding whether typical antipsychotics produce an improvement in them that is comparable with atypical antipsychotics or inferior to them (Green et al, 2002; Harvey et al, 2005; Keefe et al, 2006; Mishara and Goldberg, 2004; Remillard et al, 2005; Rollnik et al, 2002; Medalia et al, 1988; Stip et al, 2005; Lublin et al, 2005).

Increasing efforts are focused on developing drugs with robust benefits for cognitive deficits of schizophrenia. However, several limitations hamper this effort, including a relative dearth of well-established and validated animal models for these deficits. No single preclinical test is most likely to model all domains of cognitive deficits of schizophrenia. As the pathophysiology of cognitive deficits of schizophrenia, similar to noncognitive deficits of schizophrenia, is not well understood, developing animal models with etiological validity is challenging. Establishing 
predictive validity for cognitive deficits of schizophrenia presents another vexing problem, as there are no established treatments with complete efficacy.

Pragmatic issues represent yet another limitation to the development of new treatments for cognitive deficits of schizophrenia. Most preclinical cognitive tests are labor intensive, requiring the training of animals on a task for several consecutive days and thus hampering the ability to conduct high-throughput drug screening.

Paradigms examining novelty recognition in animals have been proposed as a valuable preclinical model of cognitive deficits that are seen in schizophrenia (Hagan and Jones, 2005). Social recognition and social discrimination are two related examples of preclinical paradigms that assess socially based novelty discrimination and do not require pretest training of animals (Engelmann et al, 1995).

Investigators have focused previously on pharmacological approaches to induce, in animals, cognitive deficits seen in schizophrenia. For example, Terranova et al (2005) demonstrated that acute administration of the psychotomimetics PCP and D-amphetamine disrupted social discrimination in Wistar rats. In addition, they found that subchronic administration of PCP during the neonatal period produced spontaneous deficits in social discrimination in adult rats. These deficits were reversed by the atypical antipsychotics clozapine and amisulpride and the putative atypical antipsychotic SSR 181507 (Terranova et al, 2005). These findings suggest that drug-induced disruption of social discrimination may be a useful animal model of cognitive deficits of schizophrenia with predictive utility for potential procognitive drugs. However, in regards to developing animal models with optimal utility for drug discovery, pharmacologically induced social discrimination deficits have the potential to introduce added experimental complexity, data variability, as well as potentially limiting drug discovery to agents which specifically block the effects of the deficit-inducing drug (Floresco et al, 2005). An animal model based on innate social discrimination deficits could therefore provide a complementary alternative approach to those that required experimental manipulation.

Brattleboro (BRAT) rats are Long-Evans (LE)-derived rats with a single-gene mutation that disrupts vasopressin secretion (Birkett and Pickering, 1988). BRAT rats homozygous for the mutation display a number of behaviors that are characteristic of those seen in schizophrenia patients, including abnormalities in memory (Laycock et al, 1983), stress reactivity (Williams et al, 1985), social recognition (Engelmann and Landgraf, 1994), motivation (Williams et al, 1983) and attention (Williams et al, 1983) (also see Jentsch et al, 2003). We have shown that BRAT rats exhibit natural schizophrenia-like deficits in prepulse inhibition of startle (PPI), a measure of sensorimotor gating processes. Furthermore, these PPI deficits are reversed by antipsychotics but not nonantipsychotic psychotropics. These findings suggest that the BRAT rat may be a good genetic animal model with predictive validity for antipsychotic drug efficacy. BRAT rats have been shown to exhibit social recognition deficits (Engelmann and Landgraf, 1994). Preliminary exploratory studies from our laboratory showed that BRAT rats also appeared to exhibit deficits compared with LE rats in social discrimination.
This study had several goals. First, we sought to confirm that BRAT rats exhibit natural social discrimination deficits. We also sought to begin to investigate the response of social discrimination deficits in BRAT rats to antipsychotics and putative antipsychotics that have been associated with procognitive effects. In that regard, we tested the effects of the atypical antipsychotic clozapine on social discrimination in BRAT and LE rats, as clozapine has been shown to improve learning and delayed recall in schizophrenia patients (Woodward et al, 2005), two cognitive features required for social discrimination. Furthermore, clozapine reverses the PPI deficits in BRAT rats (Feifel et al, 2004, 2007) and scopolamine-induced social discrimination deficits in rats (Terranova et al, 2005). We also tested PD149163, which is a brain-penetrating agonist of the neurotensin-1 receptor. PD149163 is a putative antipsychotic drug, reversing PPI deficits in BRAT rats (Feifel et al, 2004, 2007) and showing procognitive effects in novel object recognition, a preclinical test similar to social discrimination (Azmi et al, 2006).

\section{METHODS}

\section{Animals}

Experimental procedures were conducted in accordance with the University of California, San Diego guidelines for animal care and experimentation. All animals were purchased from Harlan Laboratories (San Diego, CA). Ninetyeight adult male BRAT rats and 68 adult male LE rats (170$350 \mathrm{~g}$ at testing) were housed in groups of two or three in clear plastic chambers in a climate-controlled room under a 12/12 h light/dark schedule (lights on/off-0700/1900). Male Sprague Dawley juvenile rats (25-30 days old) were used as social stimuli. All rats were allowed free access to food and water for the extent of the study. Behavioral testing was performed no earlier than 7 days after the animals' arrival from the breeder. Each adult and each juvenile rat was used only one time.

\section{Behavioral Procedure}

The social discrimination procedure was modified from the social recognition test described by Engelmann et al (1995). The social discrimination apparatus is made of a large plastic tub $(30 \times 17 \times 12$ inch $)$ consisting of two small wire cages $(6.5 \times 5 \times 4$ inch $)$ on either ends of the large tub in which the juvenile rats were placed. The purpose of the small wire cages was to restrict the mobility of juvenile rats, whereas allowing the adult rat visual, olfactory, and tactile access to the juveniles. This eliminated social contact that was initiated by the juveniles toward the adult. It also prevented simultaneous contact of the adult rat with both juveniles as well as juvenile-juvenile interaction, simplifying social interaction scoring. Each test trial included one adult rat, one familiar, juvenile exposed previously (familiar juvenile), and one novel juvenile. The social discrimination paradigm is illustrated in Figure 1. Briefly, adult rats acclimate in the social discrimination box for $20 \mathrm{~min}$. Following this acclimation period, the learning trial begins with the adult rat exposed to a juvenile rat in one of the two small wire cages, randomly selected, for $4 \mathrm{~min}$. The adult rat 


\section{Acclimation \\ (20 minutes)

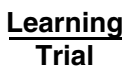 \\ $(4$ minutes) \\ Break \\ (30 minutes) \\ Test Trial \\ (4 minutes)}

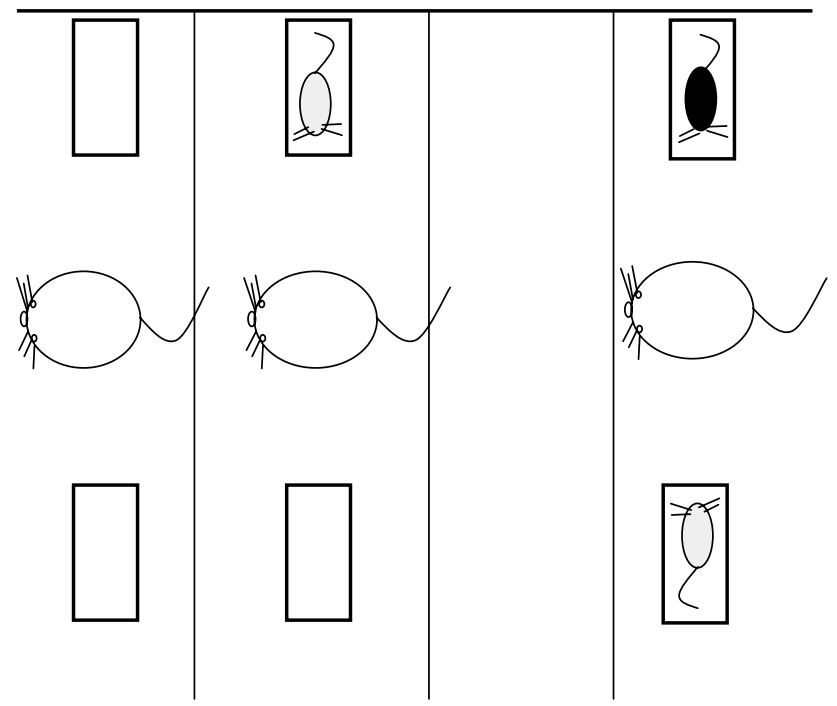

Figure I Illustration of the Social Discrimination Paradigm. Adult rats acclimate in the social discrimination box for $20 \mathrm{~min}$. Following this acclimation period, the learning trial begins with the adult rat exposed to a juvenile rat for $4 \mathrm{~min}$. The adult rat is then returned to its home cage for $30 \mathrm{~min}$. During the retrieval trial, the adult animal returns to the chamber with the introduction of a new juvenile along with the same juvenile from the learning trial for $4 \mathrm{~min}$. The positions of the juveniles are randomly alternated.

is then returned to its home cage for $30 \mathrm{~min}$. During the test trial, the adult animal is returned to the social discrimination box. Then the familiar juvenile, along with a novel juvenile, is placed in the two wire cages. In half the trials, the familiar juvenile returns to the same wire cage that the animal was initially placed in during the learning trial. In the other half of the trials, the rat is placed in the alternate wire cage. The adult rat is allotted $4 \mathrm{~min}$ to explore the juveniles. All sessions in the social discrimination box are videotaped and the tapes are scored by two raters blinded to the drug treatment and the strain of the rats. Each rater records the time each adult rat spent exploring the juvenile during learning trial, and the time the animal spent with the familiar and unfamiliar juvenile during the subsequent test trial.

\section{Drug Treatment}

Ten minutes before the acclimation period, animals were injected subcutaneously with saline, clozapine $(0.1,1$, $10 \mathrm{mg} / \mathrm{kg})$, or PD149163 $(0.1,0.3$, or $1.0 \mathrm{mg} / \mathrm{kg})$. Social discrimination was then evaluated as described above. These doses selected for clozapine and PD149163 were based on the dose range found to be effective in reversing PPI deficits occurring naturally in BRAT rats and induced by psychotomimetics (Feifel et al, 1999, 2003, 2004, 2007). Clozapine was obtained from Sigma Chemicals (St Louis, MO) and PD149163 was provided with the courtesy of NIMH Chemical Synthesis and Drug Supply program and RTI International (Research Triangle Park, NC). Clozapine was dissolved in half volume $\mathrm{HCl}$ and half volume $0.9 \%$ saline, then titrated with $\mathrm{NaOH}$ to $\mathrm{pH}$ 7. PD149163 was dissolved in $0.9 \%$ saline. Drugs were administered subcutaneously at a concentration of $1 \mathrm{ml} / \mathrm{kg}$.

\section{Statistical Analysis}

Data from animals that did not display any interaction (zero seconds) with a juvenile in either the learning or test periods were not included in the analysis, as animals that did not investigate the juvenile during the learning phase could not be used to generate data on the test trial that could legitimately be considered a reflection of their retention of previous exposure to the juvenile. Similarly, any rat that displayed zero investigation of both novel and familiar juveniles during testing displayed noninvestigatory behavior that cannot be considered as a valid test of social memory. Ten LE and 19 BRAT rats given PD149163 and 2 LE and 10 BRAT rats given clozapine were, therefore, eliminated as was one BRAT rat given saline.

A Discrimination Index was calculated to determine preference of adult rats for exploration of the novel juvenile relative to the familiar juvenile in the test session. This index was calculated for each adult rat as proportion increase above the time each animal spent exploring the familiar juvenile using the following formula: [(time exploring novel juvenile-time exploring familiar juvenile)/(time spend exploring familiar juvenile + time spent exploring novel juvenile)] (Grayson et al, 2007; Southam et al, 2009). Data were analyzed using the SPSS Explore function and extreme outliers ( $>3$ standard deviations from the mean) were excluded from the analysis. One LE rat in the high-dose clozapine group and one LE rat in the highdose PD149163 group were considered as outliers using this analysis.

To determine whether each strain exhibited social discrimination under baseline (saline) conditions, absolute time spent with familiar juvenile and novel juvenile were compared using separate paired samples $t$-test for salinetreated LE and BRAT rats.

For LE rats, Discrimination Index, time exploring juvenile in the learning phase, time spent exploring familiar juvenile during test phase, and time spent exploring the novel juvenile during the test phase were each subjected to separate one-way ANOVAs with Drug Treatment as a between-subject factor having seven elements (saline, clozapine $\times 3$ doses, PD149163 $\times 3$ doses). Drug effects for BRAT rats were assessed separately using an identical approach. Significant effects were followed up with pairwise post hoc comparisons using Fishers LSD. Alpha was set at 0.05 .

\section{RESULTS}

\section{Baseline Social Discrimination}

As shown in Table 1, saline-treated LE rats spent significantly more time with the novel juvenile compared with familiar juvenile $(t(23)=-2.80, P=0.01)$, whereas there was no significant difference between the time spent with novel and familiar juveniles among saline-treated BRAT rats (Table 2). There was no significant difference 
Table I Social Interaction Time (s) Exhibited by Long-Evans rats

\begin{tabular}{|c|c|c|c|c|c|c|c|}
\hline \multirow{2}{*}{ Trial } & \multirow{2}{*}{ Saline } & \multicolumn{3}{|c|}{ Clozapine (mg/kg) } & \multicolumn{3}{|c|}{ PDI 49 I63 (mg/kg) } \\
\hline & & 0.1 & 1.0 & 10 & 0.01 & 0.3 & 1.0 \\
\hline Test period_novel juvenile & $75.25 \pm 7.06^{\#}$ & $53.37 \pm 7.43$ & $57.14 \pm 11.49$ & $65.00 \pm 12.75$ & $69.00 \pm 14.43$ & $79.50 \pm 13.47$ & $60.29 \pm 13.24$ \\
\hline Test period-familiar juvenile & $49.29 \pm 5.11$ & $52.13 \pm 8.60$ & $67.71 \pm 16.85$ & $60.37 \pm|6.3|$ & $62.88 \pm|2.0|$ & $61.13 \pm 17.46$ & $52.58 \pm 11.76$ \\
\hline
\end{tabular}

Mean \pm SEM

$* P<0.05$, significantly less time spent investigating vs the saline-treated rats; ${ }^{\#} P<0.05$, significantly greater compared to familiar juvenile.

Table 2 Social Interaction Time (s) Exhibited by Brattleboro Rats

\begin{tabular}{|c|c|c|c|c|c|c|c|}
\hline \multirow{2}{*}{ Trial } & \multirow{2}{*}{ Saline } & \multicolumn{3}{|c|}{ Clozapine (mg/kg) } & \multicolumn{3}{|c|}{ PDI49|63 (mg/kg) } \\
\hline & & 0.1 & 1.0 & 10 & 0.01 & 0.3 & 1.0 \\
\hline Test period_-novel juvenile & $55.10 \pm 3.90$ & $43.50 \pm 10.91$ & $41.67 \pm 8.48$ & $50.63 \pm 14.32$ & $62.64 \pm 10.57$ & $55.27 \pm 13.89$ & $66.87 \pm 14.85$ \\
\hline Test period_familiar juvenile & $47.38 \pm 3.46$ & $44.88 \pm 8.87$ & $20.67 \pm 4.4 I^{* * *}$ & $21.13 \pm 5.34 * *$ & $47.09 \pm 7.35$ & $24.09 \pm 7.94 * *$ & $31.13 \pm 8.11 *$ \\
\hline
\end{tabular}

Mean \pm SEM.

*P $<0.05$; $* * P<0.0$ I, significantly less time spent investigating vs the saline-treated rats.

between LE and BRAT rats in the average time each strain spent exploring the juvenile rats during the learning period.

\section{Effect of Clozapine and PD149163 on Social Discrimination}

As shown in Table 1, analysis of the LE data from the learning exposure period showed that there was a general tendency for clozapine and PD149163 to reduce the time spent interacting with the juvenile during the learning exposure period, although the main effect of drug treatment was not significant. Post hoc pairwise comparison indicated that the interaction time exhibited by saline-treated LE rats during the learning period was significantly higher than the interaction time exhibited by LE rats treated with the highest dose of clozapine $(P<0.05)$ and PD149163 $(P<0.05)$. Analysis of Discrimination Index data showed no significant main effect of Drug Treatment in the LE rats (Figure 2). Planned post hoc comparisons showed that the $0.3 \mathrm{mg} / \mathrm{kg}$ dose of PD149163 significantly increased the Discrimination Index relative to saline in LE rats $(P<0.05)$. There was no significant effect of either drug on the time LE rats spent interacting with the novel juvenile compared with saline. Similarly, there was no significant effect of either drug on the time LE rats spent interacting with the familiar juvenile compared with saline.

In BRAT rats, clozapine and PD149163 produced a more pronounced reduction in exploration of the juvenile during the learning period (Table 2), and this was shown as a significant main effect of Drug Treatment $\left(\mathrm{F}_{6,97}=5.48\right.$, $P<0.001)$ in this strain. Post hoc pairwise comparisons showed that BRAT rats treated with saline have significantly higher interaction times with the juvenile during the learning period compared with BRAT rats treated with all

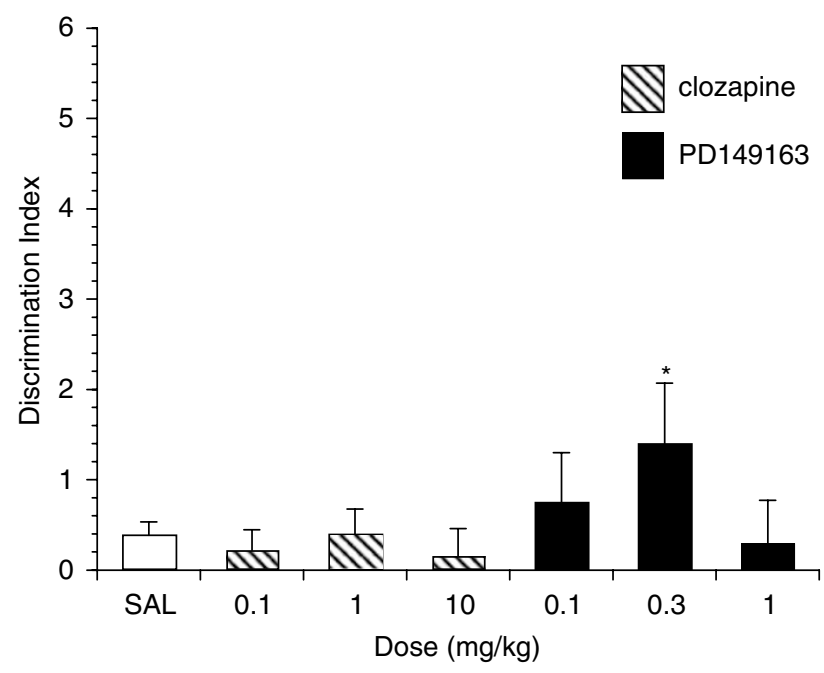

Figure 2 The effects of saline $(n=20), \operatorname{PD}|49| 63$, and clozapine ( $n=7-8$ per dose) on the Discrimination Index in LE rats. Discrimination Index equals (time spent investigating new juvenile-time spent investigating familiar juvenile)/(time spent investigating new juvenile + time spent investigating familiar juvenile). Value significantly higher than that of saline is represented by $*(P<0.05)$.

three doses of clozapine $(P=0.047, P=0.023$, and $P=0.013$, respectively) and all three doses of PD149163 tested ( $P=0.002, P<0.001$, and $P<0.001$, respectively).

Figure 3 illustrates the effects of clozapine and PD149163 on social discrimination in BRAT rats. Analysis of Discrimination Index data showed that there was a significant main effect of drug treatment $\left(\mathrm{F}_{6,97}=5.79\right.$, $P<0.001)$. Post hoc comparison showed that the highest dose of clozapine, $10 \mathrm{mg} / \mathrm{kg}(P<0.001)$, and the two highest doses of PD149163, $0.3 \mathrm{mg} / \mathrm{kg}(P<0.001)$ and $1.0 \mathrm{mg} / \mathrm{kg}$ 


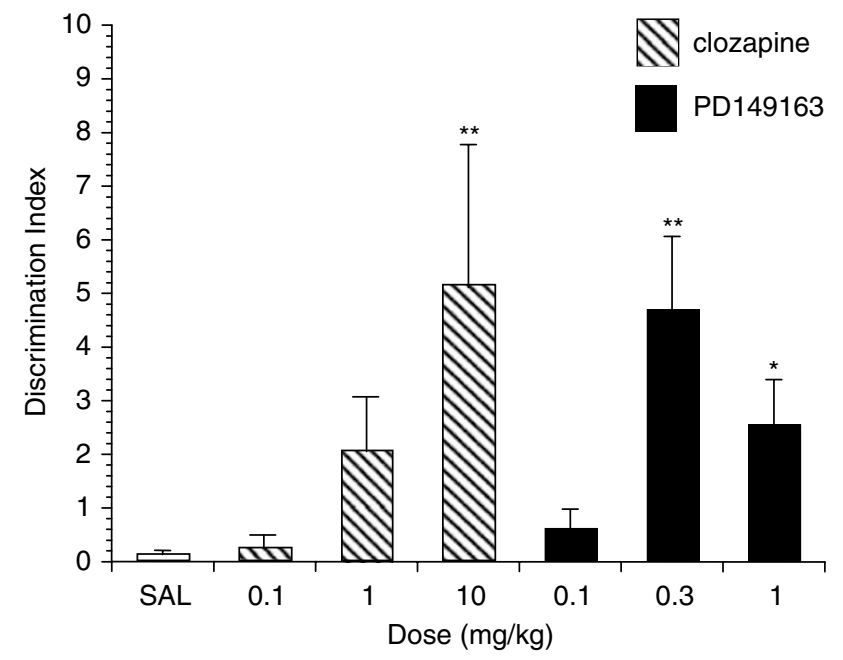

Figure 3 The effects of saline $(n=36)$, PD|49|63, and clozapine $(n=||-15$ per dose) on the Discrimination Index in BRAT rats. Discrimination Index equals (time spent investigating new juvenile-time spent investigating familiar juvenile)/(time spent investigating new juvenile + time spent investigating familiar juvenile). Values significantly higher than that of saline are represented by $*(P<0.05)$ and $* *(P<0.0 \mathrm{I})$

$(P=0.02)$, significantly increased the Discrimination Index compared with saline in BRAT rats.

Both clozapine and PD149163 decreased the time BRAT rats spent interacting with the familiar juvenile during the test period (Table 2), shown as a main effect of drug treatment $\left(\mathrm{F}_{6,104}=4.68, P<0.001\right)$. Post hoc comparisons showed that the middle and high doses of clozapine $(1.0 \mathrm{mg} /$ kg: $P<0.001 ; 10.0 \mathrm{mg} / \mathrm{kg}: P<0.001)$ and PD149163 $(0.3 \mathrm{mg} /$ kg: $P<0.001 ; 1.0 \mathrm{mg} / \mathrm{kg}: P=0.006)$ produced a significant reduction in interaction with the familiar juvenile. There was no significant effect of either drug on the time BRAT rats spent interacting with the novel juvenile compared with saline.

As seen in Table 1, neither clozapine nor PD149163 had a significant effect on the time LE rats spent with the novel juvenile during the test period. However, in BRAT rats, clozapine and PD149163 tended to produce different effects, neither of which achieved significance. Clozapine tended to decrease, whereas PD149163 tended to increase the time spent interacting with the novel juvenile.

\section{DISCUSSION}

The findings in this report confirm that BRAT rats exhibit natural social discrimination impairment, as saline-treated BRAT rats spent comparable amount of time interacting with the novel and familiar juvenile rats. In contrast, salinetreated LE rats had intact social discrimination as they spent significantly greater time interacting with the novel juvenile. The social discrimination deficits observed in BRAT rats are consistent with previous studies showing that this strain does not exhibit intact social memory in a social recognition paradigm (Engelmann and Landgraf, 1994). Moreover, the social discrimination deficit exhibited by BRAT rats seemed to be a true deficit in social memory rather than a nonspecific reduction in social motivation or general activity, as saline-treated BRAT and LE rats spent comparable time exploring the juvenile rat during the learning period.

The BRAT rat, to the best of our knowledge, is the only rat strain to display natural social discrimination deficits. Vasopressin receptor- and oxytocin receptor-null mice have also been shown to exhibit natural deficits in social memory (Bielsky et al, 2004; Wersinger et al, 2004; Winslow and Insel, 2002). Oxytocin and vasopressin are chemically and functionally related neurohormones that have both been implicated in the regulation of social behavior.

Before this study, BRAT rats were already known to display several features analogous to schizophrenia, including deficits in memory (Laycock et al, 1983), response to stress (Williams et al, 1985), motivation and attention (Williams et al, 1983), startle habituation, and prepulse inhibition (Feifel and Priebe, 2001), as well as elevated levels of striatal D2 binding (Shilling et al, 2006). The present demonstration of natural social discrimination deficits in BRAT rats adds to the schizophrenia-relevant phenotypic profile that these animals display.

In this study, the atypical antipsychotic clozapine produced a dose-dependent enhancement of social discrimination in the BRAT rats. Clozapine has been shown to reverse PCP-induced, novel object-recognition deficits, an animal test that is very similar to social discrimination (Grayson et al, 2007), and the present results are consistent with results such as these from related preclinical tests. In regards to the effects of clozapine on cognitive deficits in humans, a meta-analysis of treatment studies of schizophrenia patients showed that, overall, clozapine enhances cognitive performance in schizophrenia patients and specifically in two cognitive domains relevant to social discrimination: learning and delayed recall (Woodward et al, 2005). Therefore, it is reasonable to interpret the improvement in BRAT rat social discrimination seen with clozapine, as consistent with the clinical experience with clozapine, and thus providing preliminary predictive validity for the BRAT rat model of cognitive deficits. Tests of other antipsychotics will be needed to more conclusively establish this contention. However, establishing predictive validity for cognitive deficits of schizophrenia is not a straightforward matter, as the benefits of antipsychotics are modest and somewhat controversial. For example, while it is generally accepted that atypical antipsychotics, such as clozapine, improve cognitive deficits of schizophrenia, there is conflicting evidence regarding whether typical antipsychotics, such as haloperidol, produce improvements in cognitive deficits of schizophrenia (Green et al, 2002; Harvey et al, 2005; Keefe et al, 2006; Mishara and Goldberg, 2004; Remillard et al, 2005; Rollnik et al, 2002; Medalia et al, 1988; Stip et al, 2005; Lublin et al, 2005). Haloperidol is not effective in some animal models of cognitive deficits of schizophrenia, namely those based on PCP-induced deficits, whereas it does ameliorate the deficits in other preclinical cognitive deficits of schizophrenia models (eg, Becker and Grecksch, 2006; Dunn and Killcross, 2006; Bespalov et al, 2007). Thus, it would be harder to interpret the haloperidol findings in regards to their implications for predictive validity, and for this reason, we chose to test clozapine in this initial study of cognitive deficits in BRAT rats.

In contrast to its effects in BRAT rats, clozapine did not improve social discrimination in LE rats. In fact, it had the 
opposite effect, negating the natural social discrimination seen in saline-treated LE rats (Table 1). Therefore, the results suggest that the beneficial effects of clozapine on social discrimination were specific to the BRAT rats. This specificity is another aspect that supports the validity of the BRAT rat model for cognitive deficits of schizophrenia, as antipsychotics, such as clozapine, are not considered to be general cognitive enhancers in normal humans or patients that do not have psychotic disorders, and is considered as a cognition-impairing drug in humans who do not suffer from schizophrenia or other related psychotic disorders due to its propensity to produce anticholinergic and sedating effects.

PD149163 is an analog of neurotensin, a 13 amino-acid gut-brain peptide. Neurotensin has been proposed to be an endogenous antipsychotic due to, among other things, its ability to inhibit mesolimbic dopamine function (Kinkead and Nemeroff, 2006). Whereas neurotensin does not enter the brain after systemic administration, PD149163 was designed to do so. This compound was developed by chemically modifying the C-terminal hexapeptide fragment, neurotensin (8-13), the smallest fragment that retains the full bioactivity of neurotensin, to make it more resistant to enzymatic degradation (Banks et al, 1995). In previous preclinical studies with PD149163, we found that it produced robust antipsychotic-like effects more similar to atypical than typical antipsychotics. In BRAT rats, a single administration of PD149163 was able to reverse their PPI deficits, as did clozapine but not haloperidol (Feifel et al, 2004). This effect persisted in BRAT rats after chronic administration of PD149163 (Feifel et al, 2007). Recently, Azmi et al (2006) found that PD149163 administered to rats restored novel object recognition impaired by the anticholingergic scopolamine and the same group also reported that PD149163 increased associative learning in a trace conditioning paradigm (Grimond-Billa et al, 2008). Consistent with these findings and with clozapine effects in this study, acute administration of PD149163 improved social discrimination in this study in BRAT rats, but unlike clozapine, the most effective dose of PD149163 in BRAT rats $(0.3 \mathrm{mg} / \mathrm{kg})$ also improved social discrimination in LE rats.

The social discrimination test is based upon the social recognition test in which only the familiar juvenile is reintroduced during the testing session and reduction in time spent investigating that juvenile is evidence of intact social memory (Engelmann and Landgraf, 1994). The introduction of a second, novel juvenile in the discrimination test was used primarily to control for nonspecific reductions in investigation, for example, sedation, that might affect the second exposure. The improvement in Discrimination Index scores by clozapine and PD149163 in this study was due specifically to decrease in the time investigating the familiar juveniles, whereas investigation time of the new juveniles was not altered. Thus, the effect produced by clozapine and PD149163 of reduced exploration of the familiar juvenile is the classical operational measure of social memory (Engelmann and Landgraf, 1994).

The exact mechanisms underlying the procognitive effects of PD149163 in this and previous studies are not known. PD149163 is selective for the NT1 receptor (Petrie et al, 2004), the neurotensin receptor subtype most implicated in the antipsychotic-like effect of neurotensin. Azmi et al
(2006) speculate that the NT1-mediated enhancement of muscarinic transmission may be involved. PD149163 has also been shown to increase neuronal activation in the prefrontal cortex and this activation may contribute to its cognitive effects (Petrie et al, 2004). In any case, these results enhance the candidacy of NT1 agonists as potentially novel antipsychotics that may have benefit in treating cognitive deficits of schizophrenia. It is interesting that the dose of PD149163 that was most effective in increasing social discrimination in BRAT rats $(0.3 \mathrm{mg} / \mathrm{kg})$ also improved social discrimination LE rats. This suggests that PD149163 may facilitate nonimpaired memory.

It is noteworthy that both clozapine and PD149163 enhanced social discrimination in test trials despite the fact that both drugs reduced exploration time of LE and BRAT rats during the learning period. This reduction in exploration during the learning period is most likely due to a nonspecific inhibitory effect on activity, as both drugs are known to decrease spontaneous locomotor activity (Wiley, 2008; Norman et al, 2008). Thus, it appears that the reduction in exploratory contact during the learning period produced by clozapine and PD149163 was more than compensated for by enhanced information acquisition during this period in BRAT rats but not LE rats; in essence, PD14916 and clozapine produced more efficient learning in BRAT rats (more retention despite less opportunity to learn). This seemingly paradoxical effect has been reported with PD149163 and atypical antipsychotics in the novel object recognition test, which is similar to social discrimination (Azmi et al, 2006; Nagai et al, 2008). Indeed, among rats treated with clozapine and PD149163, there was a inverse relationship between time spent interacting with the juvenile during the learning phase and their subsequent social discrimination performance (Pearson $r=-0.182$, $P=0.06)$; the more a rat's learning period interaction was suppressed, the better they performed subsequently on social discrimination. Therefore, the mechanism underlying the reduction of spontaneous locomotion produced by these drugs may also be involved in the enhanced cognitive performance. Some rats treated with higher doses of clozapine and PD149163 had to be eliminated from the data analysis altogether, as they displayed a profound reduction in spontaneous locomotion and no interaction at all (zero seconds) with the juvenile during the learning period. It is unlikely that this selective elimination of rats contributed to the positive finding on the social discrimation performance that we observed due to the inverse relationship noted above between interaction suppression and enhancement of social discrimination.

In this study, clozapine and PD149163 improved social discrimination after a single administration. This is consistent with most other preclinical tests of antipsychotics and other cognition-enhancing treatments where significant effects are seen following a single dose. It is commonly believed that improvement of cognitive deficits of schizophrenia occurs only with chronic use of antipsychotics and not after a single dose. However, a similar common assumption about the time course of antipsychotic drug benefits on the core symptoms of schizophrenia has recently been proven inaccurate by recent meta-analyses of clinical data that show that significant benefits begin after a single dose of antipsychotics but require chronic use to 
achieve optimal effects (Agid et al, 2006, 2008). It is possible therefore that the same holds true for improvement in cognitive deficits of schizophrenia by antipsychotics, but the time course of antipsychotic-induced improvements of cognitive deficits of schizophrenia has not been studied. In this regard, we have shown that the natural PPI deficits in BRAT rats are enhanced by a single administration of atypical antipsychotics and that this effect increases with chronic administration (Feifel et al, 2007). Future studies should investigate the relative effects of acute and chronic clozapine, PD149163, and other antipsychotics on social discrimination deficits in BRAT rats.

Social discrimination abnormalities in BRAT rats, similar to the PPI deficits exhibited by this rat strain, may serve as a genetic animal model of schizophrenia cognitive deficits. Further study of this model may aid in elucidating novel genes or pathways implicated in the neuropathology of the disorder. In addition, the results of this study serve as preliminary evidence that the social discrimination deficits in BRAT rats may serve as a predictive model of novel antipsychotic efficacy in cognitive domains.

\section{DISCLOSURE/CONFLICT OF INTEREST}

Dr Feifel serves as a consultant and minor share holder for Argolyn Biosciences, which is developing novel neurotensin analogs for clinical use. Dr Feifel has received compensation for professional services (research, speaking, consultant) in the past 3 years or anticipates compensation in the next 3 years (for the following companies: Abbott, Addrenex, Alexza, Astra-Zeneca, Eli-Lilly, Janssen, Macneil, SanofiAventis, Shire, Wyeth). This work was funded by NIH MH070700. There are no other author conflicts.

\section{REFERENCES}

Agid O, Kapur S, Warrington L, Loebel A, Siu C (2008). Early onset of antipsychotic response in the treatment of acutely agitated patients with psychotic disorders. Schizophr Res 102: 241-248.

Agid O, Seeman P, Kapur S (2006). The 'delayed onset' of antipsychotic action - an idea whose time has come and gone. J Psychiatr Neurosci 31: 93-100.

Azmi N, Norman C, Spicer CH, Bennett GW (2006). Effects of a neurotensin analogue (PD149163) and antagonist (SR142948A) on the scopolamine-induced deficits in a novel object discrimination task. Behav Pharmacol 17: 357-362.

Banks WA, Wustrow DJ, Cody WL, Davis MD, Kastin AJ (1995). Permeability of the blood-brain barrier to the neurotensin 8-13 analog NT1. Brain Res 695: 59-63.

Becker A, Grecksch G (2006). Pharmacological treatment to augment hole board habituation in prenatal vitamin D-deficient rats. Behav Brain Res 166: 177-183.

Bespalov A, Jongen-Rêlo AL, van Gaalen M, Harich S, Schoemaker $\mathrm{H}$, Gross $\mathrm{G}$ (2007). Habituation deficits induced by metabotropic glutamate receptors $2 / 3$ receptor blockade in mice: reversal by antipsychotic drugs. J Pharmacol Exp Ther 320: 944-950.

Bielsky IF, Hu SB, Szegda KL, Westphal H, Young LJ (2004). Profound impairment in social recognition and reduction in anxiety-like behavior in vasopressin V1a receptor knockout mice. Neuropsychopharmacology 29: 483-493.

Birkett SD, Pickering BT (1988). The vasopressin precursor in the Brattleboro (di/di) rat. Int J Pept Protein Res 32: 565-572.

Buchanan RW, Davis M, Goff D, Green MF, Keefe RS, Leon AC et al (2005). A summary of the FDA-NIMH-MATRICS workshop on clinical trial design for neurocognitive drugs for schizophrenia. Schizophr Bull 31: 5-19.

Dunn MJ, Killcross S (2006). Differential attenuation of damphetamine-induced disruption of conditional discrimination performance by dopamine and serotonin antagonists. Psychopharmacology 188: 183-192.

Engelmann M, Landgraf R (1994). Microdialysis administration of vasopressin into the septum improves social recognition in Brattleboro rats. Physiol Behav 55: 145-149.

Engelmann M, Wotjak CT, Landgraf R (1995). Social discrimination procedure: an alternative method to investigate juvenile recognition abilities in rats. Physiol Behav 58: 315-321.

Feifel D, Melendez G, Priebe K, Shilling PD (2007). The effects of chronic administration of established and putative antipsychotics on natural prepulse inhibition deficits in Brattleboro rats. Behav Brain Res 181: 278-286.

Feifel D, Melendez G, Shilling PD (2003). A systemically administered neurotensin agonist blocks disruption of prepulse inhibition produced by a serotonin-2A agonist. Neuropsychopharmacology 28: 651-653.

Feifel D, Melendez G, Shilling PD (2004). Reversal of sensorimotor gating deficits in Brattleboro rats by acute administration of clozapine and a neurotensin agonist, but not haloperidol: a potential predictive model for novel antipsychotic effects. Neuropsychopharmacology 29: 731-738.

Feifel D, Priebe K (2001). Vasopressin-deficient rats exhibit sensorimotor gating deficits that are reversed by subchronic haloperidol. Biol Psychiatry 50: 425-433.

Feifel D, Reza TL, Wustrow DJ, Davis MD (1999). Novel antipsychotic-like effects on prepulse inhibition of startle produced by a neurotensin agonist. J Pharmacol Exp Ther 288: 710-713.

Floresco SB, Geyer MA, Gold LH, Grace AA (2005). Developing predictive animal models and establishing a preclinical trials network for assessing treatment effects on cognition in schizophrenia. Schizophr Bull 31: 888-894.

Gold JM (2004). Cognitive deficits as treatment targets in schizophrenia. Schizophr Res 72: 21-28.

Grayson B, Idris NF, Neill JC (2007). Atypical antipsychotics attenuate a sub-chronic PCP-induced cognitive deficit in the novel object recognition task in the rat. Behav Brain Res 184: 31-38.

Green AI, Tohen MF, Hamer RM, Strakowski SM, Lieberman JA, Glick I et al (2004). First episode schizophrenia-related psychosis and substance use disorders: acute response to olanzapine and haloperidol. Schizophr Res 66: 125-135.

Green MF (2006). Cognitive impairment and functional outcome in schizophrenia and bipolar disorder. J Clin Psychiatry 67: e12.

Green MF, Kern RS, Braff DL, Mintz J (2000). Neurocognitive deficits and functional outcome in schizophrenia: are we measuring the 'right stuff? Schizophr Bull 26: 119-136.

Green MF, Marder SR, Glynn SM, McGurk SR, Wirshing WC, Wirshing DA et al (2002). The neurocognitive effects of low-dose haloperidol: a two-year comparison with risperidone. Biol Psychiatry 51: 972-978.

Grimond-Billa SK, Norman C, Bennet GW, Cassaday HJ (2008). Selectively increased trace conditioning under the neurotensin agonist PD149163 149163 in an aversive procedure in which SR 142948A was without intrinsic effect. J Psychopharmacol 22: 290-299.

Hagan JJ, Jones DN (2005). Predicting drug efficacy for cognitive deficits in schizophrenia. Schizophr Bull 31: 830-853.

Harvey PD, Rabinowitz J, Eerdekens M, Davidson M (2005). Treatment of cognitive impairment in early psychosis: a comparison of risperidone and haloperidol in a large long-term trial. Am J Psychiatry 162: 1888-1895.

Jentsch JD, Arguello PA, Anzivino LA (2003). Null mutation of the arginine-vasopressin gene in rats slows attentional engagement 
and facilitates response accuracy in a lateralized reaction time task. Neuropsychopharmacology 28: 1597-1605.

Keefe RS, Young CA, Rock SL, Purdon SE, Gold JM, Breier A (2006). One-year double-blind study of the neurocognitive efficacy of olanzapine, risperidone, and haloperidol in schizophrenia. Schizophr Res 81: 1-15.

Kinkead B, Nemeroff CB (2006). Novel treatments of schizophrenia: targeting the neurotensin system. CNS Neurol Disord Drug Targets 5: 205-218.

Laycock JF, Gartside IB, Chapman JT (1983). A comparison of the learning abilities of Brattleboro rats with hereditary diabetes insipidus and Long-Evans rats using positively reinforced operant conditioning. Prog Brain Res 60: 183-187.

Lublin H, Eberhard J, Levander S (2005). Current therapy issues and unmet clinical needs in the treatment of schizophrenia: a review of the new generation antipsychotics. Int Clin Psychopharmacol 20: 183-198.

Medalia A, Gold J, Merriam A (1988). The effects of neuroleptics on neuropsychological test results of schizophrenics. Arch Clin Neuropsychol 3: 249-271.

Mishara AL, Goldberg TE (2004). A meta-analysis and critical review of the effects of conventional neuroleptic treatment on cognition in schizophrenia: opening a closed book. Biol Psychiatry 55: 1013-1022.

Nagai T, Murai R, Matsui K, Kamei H, Noda Y, Furukawa $\mathrm{H}$ et al (2008). Aripiprazole ameliorates phencyclidine-induced impairment of recognition memory through dopamine $\mathrm{D}(1)$ and serotonin 5-HT (1A) receptors. Psychopharmacology 202: 315-328.

Norman C, Grimond-Billa S, Bennett G, Cassaday H (2008). A neurotensin agonist and antagonist decrease and increase activity, respectively, but do not preclude discrete cue conditioning. J Psychopharmacology 2008 (E-pub).

Petrie KA, Bubser M, Casey CD, Davis MD, Roth BL, Deutch AY (2004). The neurotensin agonist PD149163 increases Fos expression in the prefrontal cortex of the rat. Neuropsychopharmacology 29: 1878-1888.

Remillard S, Pourcher E, Cohen H (2005). The effect of neuroleptic treatments on executive function and symptomatology in schizophrenia: a 1-year follow up study. Schizophr Res 80: 99-106.
Rollnik JD, Borsutzky M, Huber TJ, Mogk H, Seifert J, Emrich HM et al (2002). Short-term cognitive improvement in schizophrenics treated with typical and atypical neuroleptics. Neuropsychobiology 45: 74-80.

Shilling PD, Kinkead B, Murray T, Melendez G, Nemeroff CB, Feifel D (2006). Upregulation of striatal dopamine-2 receptors in Brattleboro rats with prepulse inhibition deficits. Biol Psychiatry 60: $1278-1281$.

Southam E, Cilia J, Gartlon JE, Woolley ML, Lacroix LP, Jennings CA et al (2009). Preclinical investigations into the antipsychotic potential of the novel histamine $\mathrm{H}(3)$ receptor antagonist GSK207040. Psychopharmacology 201: 483-494.

Stip E, Chouinard S, Boulay LJ (2005). On the trail of a cognitive enhancer for the treatment of schizophrenia. Prog Neuropsychopharmacol Biol Psychiatry 29: 219-232.

Terranova JP, Chabot C, Barnouin MC, Perrault G, Depoortere R, Griebel $G$ et al (2005). SSR181507, a dopamine $\mathrm{D}(2)$ receptor antagonist and 5-HT(1A) receptor agonist, alleviates disturbances of novelty discrimination in a social context in rats, a putative model of selective attention deficit. Psychopharmacology (Berl) 181: 134-144.

Wersinger SR, Kelliher KR, Zufall F, Lolait SJ, O'Carroll AM, Young III WS (2004). Social motivation is reduced in vasopressin $1 \mathrm{~b}$ receptor null mice despite normal performance in an olfactory discrimination task. Horm Behav 46: 638-645.

Wiley JL (2008). Antipsychotic-induced suppression of locomotion in juvenile, adolescent and adult rats. Eur J Pharmacol 578: 216-221.

Williams AR, Carey RJ, Miller M (1983). Behavioral differences between vasopressin-deficient (Brattleboro) and normal Long-Evans rats. Peptides 4: 711-716.

Williams AR, Carey RJ, Miller M (1985). Altered emotionality of the vasopressin-deficient Brattleboro rat. Peptides 6(Suppl 1): 69-76.

Winslow JT, Insel TR (2002). The social deficits of the oxytocin knockout mouse. Neuropeptides 36: 221-229.

Woodward ND, Purdon SE, Meltzer HY, Zald DH (2005). A metaanalysis of neuropsychological change to clozapine, olanzapine, quetiapine, and risperidone in schizophrenia. Int J Neuropsychopharmacol 8: 457-472. 